\title{
Research on the Impact of 3D Pattern Image to the Young People
}

\author{
Liya Wang \\ Jiangxi Institute of Fashion Technology, Nanchang, China \\ âFenqin@163.com
}

\begin{abstract}
Keywords: Children's Clothing Patterns, Adult, Trends, Children's Intelligence
\end{abstract}
\begin{abstract}
With the rapid development of China's garment industry segments and children's consumer market, the adult trend of children's clothing is getting worse. This paper aims to depart from the children's clothing patterns and other trends, investigate the causes of the adult trend of children's clothing and its impact on children and then put forward rationalization proposals on children's clothing designs.
\end{abstract}

\section{Introduction}

With the real parent-child interaction program "Where is the father," the hit, not only by everyone getting parenting topics of common concern, the first line of the play stars the children also gave birth to the prosperity of children's clothing market. In recent years, although there have been changes in children's wear market diversity, but because of domestic Kids start time is not long, children's consumer culture has long been replaced by the adult mentality. Adult clothing trends, by definition refers to children's clothing designed in accordance with the adult costume design, the children's clothing as a smaller version of an adult, these are reflected in the use of models to determine the style of clothing, such as color and pattern of market trends in both. Kids adult concept is as foreign children's clothing design style descendant of the Chinese market. Kids and adults internationally, and its purpose is to pursue the style of simple, elegant and soft pastel colors to meet some high-grade consumer demands. For children's clothing patterns adult fashion trends change, contrary to the children's physical and psychological development of the rules and characteristics, physical and mental development of young children had a tremendous negative impact, and even some of the children formed a love vanity, love comparisons of "Peacock mentality". Kids in the design study, the lack of research on a regular basis on the child's own physical and psychological characteristics, resulting in domestic children's clothing is still hovering in the low-end of the level.

Children is a particular group, in the dress should be with children, adolescents and adults incomparable place. Clothing colors, patterns, styles style and fabric selection to inspire children's creativity play a crucial role, especially in the choice of colors and patterns. Color is the visual gives the first impression, can stimulate the brain and promote brain cell growth and development, to stimulate children's creativity and imagination. The emergence of a variety of different styles of patterns, not only the clothing has become a vibrant, interesting, but also help stimulate the child's imagination is rich visually, but also self-training speech and language ability, sound thinking and intellectual development. If the child can often wore rich colors, styles, patterns novelty clothing for children's mood will be highly beneficial for physical and mental training. The children dress for early childhood development without considering the characteristics of the impact on their physical and mental development exists.

Now you can see a lot of children's clothing from style to fabric to color very adult, the adult clothing to reduce the size to become a children's clothing on the children's wear market, which is contrary to the trend of adult children's clothing infant physiological and psychological development characteristics of children affects both physical and mental development, "dress to change people's mood can change people's perception of him, the United States can enhance people's self-confidence dress" for pride was hurt, no self-confidence of children, change of dress is an effective the approach "to wear decent clothes make people get back the feeling of 
self-confidence in order to state and national prosperity, care about their children grow up, to promote quality education early childhood develop children's artistic, and aesthetic taste, constantly changing dress for children, physical and mental development of young children and intellectual development has great practical significance.

\section{The Impact of the Adult Trend of Children's Clothing Patterns on Children}

The Adult Trend of Children's Clothing Patterns Hinders the Development of Children's Imagination and Creativity. This age is a critical period of thinking, cognitive development, and for children to grasp the acquisition of knowledge, understanding of the world play a crucial role. Children and more figurative association, specific image pattern is the main intermediary and sign this stage children thinking, knowledge of the world entirely through specific image in mind to think, so the children's decorative patterns can also become early intellectual development of children focus. • German philosopher Ernst Cassirer famous man directly defined as "the symbol of animals," he said in his famous "man" theory: "We did find one where a particular type of animal in the world that are not relationship thinking ", and" thought the relationship depends on the ideological symbol [1]. Cognitive level of the child at this stage to determine its perception of things is a simple, flat, clothing pattern itself is equivalent to a symbol, because it is a popular spread to accomplish its mission by means of symbolic information carrier.

From children's clothing patterns on the market today, the adult tendency to make children's clothing style increasingly sophisticated, adult-oriented for the international children's fashion trends, different companies have different interpretations, but to completely move closer to adult children's clothing styles areas, the trend is understandable that biased. Most take a more adult-oriented non-color children's clothing with the adult color pattern, although more stable but visually boring, not enough distinctive personality. Kids in some designs is also no longer confined to cartoons and other lovely shape, there has been a symbol of terrorist violence called abstract pattern personality pirates, skeletons, swords and guns and so on. Pattern of decorative techniques are also being replaced in many adult clothing shiny beads, ribbons, metal chains, rivets, sharp hard these skin jewelry will harm children, too cumbersome decor is not conducive to children's focus ability to learn. Kids appear in adult-oriented colors and patterns do not meet the psychological characteristics of children, is not conducive to early childhood imagination, develop creativity.

The Adult Trend of Children's Clothing Patterns Hinders Children to Establish a Correct Outlook on Life and Values. China's economic development so that people's lives have been greatly improved, directly affects consumer attitudes. Now the child has become the focus of an average family, shot more and more generous when parents buy clothes for their children. Children's clothing designs on the market, mostly in reference to adult-oriented trend, both to meet the psychological growth of children, more focus on the psychological study of adults. Children growing easy to put attention on their clothing and appearance, often find their psychological orientation from their worn clothes, over time will gradually form a love vanity, love of competition, materialistic enjoyment, "Peacock mentality."

American psychologist Georgia Witkin also said people dress and behavior of children of the same age can easily cause a wave of imitators. Precocious Puberty renowned expert Professor SHEN Yong said the children had early exposure in adult environment, are likely to cause precocious puberty. Children's ability to resist frustration, independent personality are not mature, life, values and aesthetics are required to give a reasonable adult guidance, children lovely nature. Kids now in leopard, lace and other patterns to guide children in the adult world in the pursuit of sexy, is not conducive to the physical and mental development of children. Rousseau once said:. "Before they did not grow up, they would like an adult, which is harmful to their physical and mental health." So children's clothing pattern design should be childlike, not blindly pursue adult and blindly comply with adult clothing fashion trend [2]. Children's clothing designs in the absorption of adult pop elements, but also take into account the child's psychological characteristics, so that children establish a correct outlook on life and values, the values of the parents do not affect the child with the adult world, luxury material can only be brought to the children temporary 
happiness.

\section{The Aesthetic Features and Intellectual Enlightenment Educational Role of Children's Clothing Decorative Patterns}

Children's Clothing Pattern Design Should Strengthen Aesthetic Features. Dress patterns are beautiful things can be directly used to feel the concrete sensory images. But aesthetic way children and adults and aesthetic taste is very different, especially children younger children thinking of clothing still in the stage of simple figurative forms plane, its grasp on the world around them is often integrated with a natural manner. Children for text recognition capability is not strong, but appeared on a local clothing patterns and colors of these garments are very interested in, so that must have children like pockets, buttons, patterns and so on children's clothing, the intention is also precisely in order to attract children's attention. Most of the time the child is a collective activity undertaken, using graphic language and children for effective transmission of information dissemination may also facilitate the promotion of children's clothing brand [3].

The study found that the children's clothing with good cognitive abilities plays a very important role children's cognitive, emotional, games, learning activities,. For example, a variety of lovely animals and cartoon characters on children's clothing, children's clothing patterns on some using letters, numbers and other elements, to a certain extent reflects the awareness of early education, these patterns not only stimulate the child's imagination is rich visually, but also promote the child's imagination and creativity of children's thinking and mental development has played a role in enlightening education. So use on children's cognitive patterns inspired by children's play a crucial role. And children are more receptive to further cognitive elements into children clothing, so that children clothing cognitive educational and life practicality connected. Kids dress patterns urgent need to find better ways to design, create, and children on the outside of things, mainly from an intuitive understanding of the appearance of irritation, and can beautify the image of children's clothing, so that children get more enjoyment of beauty.

The Intellectual Enlightenment Educational Role of Children's Clothing Decorative Patterns. Decorative pattern design is the focus of children's clothing design, decorative patterns can not only beautify the children's clothing, children bring to the art of the self-experience, and on the growth of children also have a subtle influence, but also to promote their mental growth. Research shows that a normal amount of information in all kinds of organs obtained through the eyes of more than 95\% is obtained through. Therefore, the human eye is an important sensory organ of the brain access to external information. Psychologists have stressed that development should be placed on top of the visual capabilities of early childhood intellectual development. Aesthetic clarity with respect to children and adults in terms of logic is with arbitrariness. Children love to see more concrete images of fantasy, under the influence of mood and feeling, aesthetic children's clothing is uncertain, and always changing. They are often like today, tomorrow, not like it. The children see what was beautiful, mainly to see interesting disappointed, but fun in life is varied. There are vulgar, healthy and happy, elegant noble, there are simple natural and so on. Respond to the child's interest to guide, make the best use, so that the child's interest along the positive, healthy direction. Penetration dissemination of culture is usually accomplished through a variety of ways. [4]

With the spread of the animation culture, many children and animation-related industrial chain also will spread. Cartoon on the era, the children simply to look at, but in recent years the cartoon, but in subtly guide the parents and the children's consumer awareness. Nowadays, television hit cartoon "Pleasant Goat and Big Wolf" and "bear-infested" and other interesting demeanor, not only reflects the innocence of children, but also to having Pleasant, head strong, bear pattern Kids on warmly welcomed. They continue to be the children's favorite, the impact of their words and deeds, and consumer attitudes. The main advantage is that cross-border animation has a strong penetration ability to closely integrate physical and clothing industry, the formation of all clothing cultural and emotional identity. The main features of the cartoon style pattern is exaggerated and distorted, so that the performance of the more distinctive features, more typical and full of emotion, and has the effect of strengthening the narrative and the teaser. With a strong subjective spiritual color, the 
prototype can be mutated to create a formal beauty, the ideal beauty of the artistic image. Fun bright colors, rich and varied patterns can best stimulate interest in children. Kids should be reflected in designs without losing its basic function of the nature of children, pay attention to the visual ability of training and training, intellectual development of the child in the future will play a positive role in promoting [5].

\section{Conclusions}

Seen in this light, it should make child's clothing restore "children" as soon as possible and at the same time which requires the designers make an effort on children's clothing designs to make children's clothing designed "product" and "taste" and let the r children to wear the clothes and percept into the world.

\section{References}

[1] Meixia Li: Journal of Tianjin Textile Institute of Technology, Vol. 5 (2000) No 22, p.93-96

[2] Yun Tang, Zhanfei Xiong: Progress in Textile, Vol. 3 (2011) No 13, p.34-36

[3] Shilong Fan: Light Industry Science and Technology, Vol. 11 (2010) No 13, p.45-47

[4] Xiaoping Zhang, Junze Wang: Knitting Industries, Vol. 9(2011). No10, p12-14

[5] Qiujuan Li, Bing Zhang: Light Industry Science and Technology, Vol. 3 (2010) No 12, p.25-27 